\title{
J.-C. Dumoncel, La mathesis de Marcel Proust
}

\section{Chiara Nifosi}

\section{(2) OpenEdition}

\section{Journals}

\section{Edizione digitale}

URL: http://journals.openedition.org/studifrancesi/10042

DOI: 10.4000/studifrancesi. 10042

ISSN: 2427-5856

\section{Editore}

Rosenberg \& Sellier

\section{Edizione cartacea}

Data di pubblicazione: 1 août 2017

Paginazione: 393-394

ISSN: 0039-2944

\section{Notizia bibliografica digitale}

Chiara Nifosi, «J.-C. Dumoncel, La mathesis de Marcel Proust», Studi Francesi [Online], 182 (LXI | II) |

2017, online dal 01 août 2017, consultato il 06 janvier 2021. URL: http://journals.openedition.org/ studifrancesi/10042 ; DOI: https://doi.org/10.4000/studifrancesi.10042

\section{Questo documento è stato generato automaticamente il 6 janvier 2021}

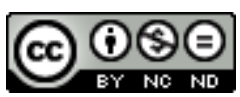

Studi Francesi è distribuita con Licenza Creative Commons Attribuzione - Non commerciale - Non opere derivate 4.0 Internazionale. 


\title{
J.-C. Dumoncel, La mathesis de Marcel Proust
}

\author{
Chiara Nifosi
}

\section{NOTIZIA}

JEAN-ClaUde DUMONCEL, La mathesis de Marcel Proust, Paris, Classiques Garnier, 2015, «Bibliothèque proustienne» 13, $786 \mathrm{pp}$.

1 Grazie all'apporto delle numerose discipline che convergono nella sua attenta analisi del testo proustiano, Jean-Claude Dumoncel cerca di rivelarne un'estrema e inedita fecondità. Il proposito dell'autore è, da un lato, "spiegare" il romanzo di Proust grazie all'applicazione della logica modale, dall'altro, definire le implicazioni della sua ricezione in quanto "strumento pedagogico" (p. 13).

2 Nell'Introduzione (pp. 13-64), Dumoncel colloca la propria analisi nelle due dimensioni, indicate da Barthes, di «mathesis» e «mandala» (p. 18), ovvero i due estremi dello spettro del pensiero umano entro cui si situa la Recherche. La densità filosofica del romanzo è dunque volta a superare l'opposizione fra scienze esatte e cosmologia (p. 21). Premessa di tale impresa è il riconoscimento di uno stato di crisi: a una rappresentazione globale del mondo - il mandala di stampo teologico - corrisponde l'ambizione di rimuovere gli ostacoli della storia (p. 35).

3 Nella prima parte, Dumoncel descrive la geometria dell'universo proustiano a partire dal celebre cono rovesciato di Bergson, rispetto al quale egli mette in evidenza analogie e differenze. La geometria proustiana appare ben lontana dalla geometria dei matematici - e in questo risiede la forza del libro di Dumoncel, ovvero nel non perdere mai il contatto con la realtà romanzesca: la geometria entro cui si muove il narratore è «mouvante» ed «émouvante» al tempo stesso (p. 79), poiché si modella sulle dinamiche amorose, vero centro strutturale del romanzo. L'autore sposta la sua argomentazione sul piano stilistico, individuando come momento chiave della germinazione dell'opera il testo del 1907 Impressions de route en automobile, antecedente del passo sui campanili di 
Martinville (pp. 189-239). La visione dei campanili si offre come "segno", in termini deleuziani, della mobilità del sentimento e del principio di unità cui si riconduce la molteplicità delle donne amate da Marcel.

4 Dopo aver sovrapposto emblematicamente il discorso erotico-sentimentale alle considerazioni sulle strategie di guerra nella parentesi di Doncières (pp. 241-268), e aver affrontato la questione dell'identità come ventaglio di possibili realizzazioni ( $\mathrm{p}$. 347), Dumoncel si sofferma, nella terza sezione («Philosophie de l'amour»), sull'esposizione dettagliata dell'«amour modal» (p. 382), per poi passare a una lettura della geometria proustiana in relazione al pensiero di alcuni matematici tra cui Lebesgue, Borel e Poincaré, contestualizzazione fondamentale, anche se forse un po' tardiva, al fine di valutare le conoscenze effettive di Proust in materia. La quinta parte del volume individua i quattro elementi chiave del romanzo - «Le possible, les noms, les pays, les amours» - letti alla luce della logica modale, in particolare della tense logic di Prior (pp. 487-525).

5 Nella sesta e ultima parte, l'argomentazione si situa su un piano pedagogico: l'attraversamento del pensiero di John Ruskin, caratterizzato dalla diversificazione dei campi di applicazione (pp. 669-671), avrebbe contribuito a formare in Proust l'idea di fondare un nuovo mito filosofico (p. 680) che potesse agire sulla storia a partire dalla constatazione di una crisi di valori largamente rappresentata nell'universo decadente della Recherche (pp. 607-619).

L'opera si configura così come la rilettura di una serie di sistemi filosofici (Platone, Kant, Leibniz e Spinoza su tutti) attraverso il genere del romanzo, dove convergono istanze apparentemente inconciliabili, ovvero «la valeur intemporelle des chefsd'œuvre» (p. 682) e, in opposizione a essa, l'inevitabile storicizzazione a cui l'esperienza estetica è soggetta.

7 La monografia di Dumoncel ha il merito di ricorrere a un approccio interdisciplinare molto attuale e di suggerire nuove strade nell'ambito del dibattito su una possibile "filosofia di Proust". L'analisi accorta di numerosi passi impedisce tuttavia uno sconfinamento nell'extra-romanzesco, offrendo materia di riflessione per chiunque si interessi alla Recherche. 